\title{
Uji Aktivitas Tonik Rambut Nanoemulsi Minyak Kemiri (Aleurites moluccana L.)
}

Fenita Shoviantari*, Zefia Liziarmezilia, Adventa Bahing, Lia Agustina

Fakultas Farmasi, Institut Ilmu Kesehatan Bhakti Wiyata, Kediri

*Corresponding author: fenita.shoviantari@iik.ac.id

Submitted: 28 November 2019

Accepted: 3 Januari 2020

Published: 29 Februari 2020

\begin{abstract}
Background: Candlenut oil from Aleurites moluccana L. contained saponins, flavonoids and polyphenols with its activity as hair growth stimulator has been widely used for hair tonics. In this study, candlenut oil was formulated into cosmetic preparations with a nanoemulsion system for increasing penetration and activity of active substances. Nanoemulsion is a transparent emulsion that has a droplet size of $5-500 \mathrm{~nm}$. Objective: To determine activity of the nanoemulsion of candlenut oil in accelerating hair growth of male rabbits. Methods: The nanoemulsion was made using candlenut oil 5\%, Tween 80 and Span 80 as surfactants, $96 \%$ ethanol as cosurfactant, and aquadest. Evaluation of physical quality of nanoemulsion included organoleptic, droplet sizes, polydispersity index, $\mathrm{pH}$, and nanoemulsion type. The activity test was carried out in vivo using male rabbits with 4 treatment groups (conventional oil, nanoemulsion, positive and negative control group) for 21 days. Results: The nanoemulsion physical quality test showed nanoemulsion type of oil in water clear with a droplet size of $21.1 \mathrm{~nm}$ and polydispersity index of 0.338 , with a $\mathrm{pH}$ of $5.47 \pm 0.029$. The activity test showed that rabbits treated with nanoemulsion of candlenut oil had higher hair length and thickness than the other groups. Conclusion: The nanoemulsion of candlenut oil could increase hair growth activity compared to conventional candlenut oil.
\end{abstract}

Keywords: hair tonic activity, nanoemulsion, rabbit, candlenut oil

\begin{abstract}
Abstrak
Pendahuluan: Minyak kemiri (Aleurites moluccana L.) mengandung asam oleat yang tinggi dan memiliki aktivitas sebagai perangsang pertumbuhan rambut yang telah banyak digunakan secara turun temurun sebagai tonik rambut. Pada penelitian ini, minyak kemiri diformulasikan menjadi sediaan kosmetik dengan sistem penghantaran nanoemulsi yang memiliki tujuan untuk meningkatkan penetrasi dan aktivitasnya. Nanoemulsi adalah sediaan emulsi transparan yang memiliki ukuran droplet kurang dari $100 \mathrm{~nm}$. Tujuan: Untuk mengetahui aktivitas nanoemulsi minyak kemiri dalam mempercepat pertumbuhan rambut pada kelinci jantan. Metode: Nanoemulsi yang dibuat menggunakan minyak kemiri 5\%, dicampur dengan Span 80 serta Tween 80 sebagai surfaktan, etanol 96\% sebagai ko-surfaktan, dan pembawa air suling. Evaluasi mutu fisik nanoemulsi meliputi organoleptis, ukuran droplet, polydispersity index, $\mathrm{pH}$, dan tipe nanoemulsi. Uji aktivitas dilakukan secara in vivo menggunakan kelinci jantan dengan 4 kelompok perlakuan (kelompok minyak konvensional, nanoemulsi, kontrol positif dan negatif) selama 21 hari. Hasil: Hasil uji mutu fisik nanoemulsi didapatkan nanoemulsi dengan tipe minyak dalam air yang jernih dengan ukuran droplet $21,1 \mathrm{~nm}$ dan polydispersity index 0,338 dengan $\mathrm{pH} 5,47$ $\pm 0,029$. Hasil uji aktivitas menunjukkan bahwa kelinci yang diberi perlakuan nanoemulsi minyak kemiri memiliki panjang dan tebal rambut yang lebih tinggi dibandingkan kelompok lainnya. Kesimpulan: Dari hasil penelitian dapat disimpulkan bahwa nanoemulsi minyak kemiri dapat meningkatkan aktivitas pertumbuhan rambut dibandingkan dengan minyak kemiri konvensional.
\end{abstract}

Kata kunci: aktivitas penguat dan penyubur, rambut, nanoemulsi, kelinci, kemiri 


\section{PENDAHULUAN}

Rambut adalah simbol penampilan yang baik dan keindahan pada beberapa bagian tubuh manusia. Fungsi rambut antara lain adalah sebagai penentu identitas dan untuk memberikan perlindungan terhadap kondisi lingkungan, seperti cahaya matahari dan iklim dingin (Agoes, 2015). Rambut rontok merupakan salah satu masalah serius yang dialami oleh pria dan wanita. Faktor yang menyebabkan rambut rontok dibagi menjadi dua, yaitu faktor internal dan eksternal. Faktor internal yang dapat menyebabkan kerontokan rambut antara lain kelainan genetis, kondisi hormon, penyakit sistemik, status gizi, maupun intoksikasi. Sementara faktor eksternal, antara lain stimulus dari lingkungan, maupun penggunaan kosmetik rambut yang tidak cocok dengan kondisi rambut. Faktor-faktor tersebut dapat menyebabkan tidak normalnya siklus dan batang rambut, kerusakan folikel rambut hingga dapat menyebabkan kegagalan pertumbuhan rambut (Sari \& Wibowo, 2016).

Produk kosmetika untuk mengatasi masalah kerontokan rambut dapat berasal dari bahan alam maupun sintetis. Salah satu bahan aktif yang dapat digunakan sebagai anti kerontokan rambut adalah Minoksidil. Penggunaan Minoksidil sebagai penyubur rambut memungkinkan timbulnya efek samping seperti alergi kulit, sakit kepala, vertigo, edema sampai hipotensi. Dengan banyaknya efek samping dari penggunaan bahan-bahan sintetis, konsep hidup kembali pada alam mulai diminati oleh masyarakat dan didukung pula dengan melimpahnya kekayaan alam di Indonesia (Nurjanah \& Krisnawati, 2014). Masyarakat lebih banyak memilih menggunakan bahan alam sebagai pilihan kosmetika yang dianggap tidak memiliki efek samping. Salah satu bahan alam yang banyak digunakan oleh masyarakat untuk mengatasi berbagai permasalahan rambut adalah minyak kemiri.

Dalam satu biji kemiri mengandung 50\% - 60\% berat minyak. Minyak kemiri merupakan minyak dari daging biji kemiri yang memiliki kandungan asam lemak tak jenuh (asam oleat) yang tinggi (Arlene, 2013). Sifat antioksidan asam oleat dapat memperlambat kerontokan dan mempercepat pertumbuhan rambut (Sari \& Wibowo, 2016).

Nanoemulsi adalah dispersi minyak berukuran nanometer yang transparan, stabil secara termodinamika yang distabilkan oleh surfaktan dan kosurfaktan dengan ukuran droplet $10-100 \mathrm{~nm}$. Nanoemulsi memiliki banyak keuntungan, diantaranya adalah dapat meningkatan active ingredient loading dan bioavailabilitasnya. Selain itu, nanoemulsi juga dapat menjadi salah satu sistem untuk tujuan drug targeting dan juga drug controlled release (Vivek, 2019). Penggunaan mikroemulsi pada kulit dapat meningkatkan penetrasi dan absorpsi bahan aktif tanpa perlu menambahkan eksipien penetrasi lain karena droplet mikroemulsi memiliki luas permukaan yang besar sehingga lebih efektif sebagai sistem pembawa (Lina dkk., 2017).

Surfaktan yang umumnya digunakan pada sediaan nanoemulsi adalah golongan nonionik. Golongan ini lebih dipilih karena sifatnya yang lebih non iritatif. Dalam kebanyakan kasus penggunaan surfaktan saja tidak cukup mampu menurunkan tegangan permukaan antara minyak dan air sehingga dibutuhkan bantuan kosurfaktan untuk membantu menurunkan tegangan permukaan. Kosurfaktan memiliki fungsi untuk menaikkan mobilitas ekor hidrokarbon sehingga penetrasi minyak pada bagian ekor menjadi lebih besar (Gupta dkk., 2010).

Pada penelitian ini, minyak kemiri yang biasa digunakan secara turun menurun sebagai minyak rambut akan dibuat dalam bentuk sediaan nanoemulsi dengan tujuan untuk meningkatkan penetrasi bahan aktif menembus kulit kepala sehingga dapat meningkatkan aktivitas.

\section{BAHAN DAN METODE Bahan}

Bahan-bahan yang digunakan pada penelitian ini antara lain minyak kemiri (Supa), tween 80 (Fagron), span 80 (Techno pharmacem), etanol 96\% (Carlo erba), air suling, dan tonik rambut ginseng yang tersedia di pasaran (digunakan sebagai kontrol positif).

Alat

Alat yang digunakan pada penelitian ini antara lain neraca analitik Centaurus scale TM, Thermo Scientific тм Cimarec + тм Stirring Hotplates Series, $\mathrm{pH}$ meter, dan particle size analyzer.

\section{Metode}

\section{Pembuatan nanoemulsi minyak kemiri (Aleurites moluccona $\mathbf{L}$.)}

Prosedur pembuatan nanoemulsi minyak kemiri hair tonic dilakukan dengan cara mencampurkan minyak kemiri dengan span 80 yang diaduk dengan magnetic stirrer $800 \mathrm{rpm}$ selama 7 menit, kemudian ditambahkan tween 80 , diaduk dengan magnetic stirrer $800 \mathrm{rpm}$, selama 7 menit. Kemudian ditambahkan etanol, lalu diaduk dengan magnetic stirrer $800 \mathrm{rpm}$ selama 7 menit, selanjutnya ditambahkan air suling, 
diaduk dengan magnetic stirrer $800 \mathrm{rpm}$ selama 15 menit. Formulasi sediaan nanoemulsi minyak kemiri sebagai hair tonic tersaji pada Tabel 1.

Tabel 1. Formulasi nanoemulsi minyak kemiri

\begin{tabular}{cccc}
\hline No. & Komponen & Kegunaan & $\begin{array}{c}\text { Konsentrasi } \\
(\%)\end{array}$ \\
\hline 1. & Minyak & Bahan aktif & 5 \\
& Kemiri & & \\
2. & Tween 80 & Surfaktan & 18,4 \\
3. & Span 80 & Surfaktan & 1,8 \\
4. & Etanol 96\% & kosurfaktan & 3,5 \\
5. & Air suling & Pelarut & ad 100 \\
\hline
\end{tabular}

Belum ada penelitian mengenai kadar minyak kemiri sebagai tonik rambut, sehingga pemilihan kadar 5\% minyak kemiri pada formulasi ini mengunakan pendekatan penelitian yang dilakukan oleh Ulfah yang menyatakan bahwa ekstrak etanol biji kemiri mampu meningkatkan pertumbuhan rambut kelinci (Ulfah, 2003).

\section{Pengamatan organoleptis}

Pengujian organoleptis dilakukan secara visual dengan mengamati bentuk, bau dan warna sediaan.

\section{Pengukuran pH}

pH sediaan nanoemulsi minyak kemiri diukur dengan menggunakan $\mathrm{pH}$ meter digital. Kalibrasi $\mathrm{pH}$ meter dengan larutan dapar $\mathrm{pH} 4$ dan 7 dilakukan sebelum pengujian $\mathrm{pH}$ sediaan untuk memastikan alat dapat berfungsi dengan baik. Setelah proses kalibrasi selesai, elektroda dibersihkan lalu dimasukkan ke dalam gelas Beaker yang berisi nanoemulsi minyak kemiri. Nilai $\mathrm{pH}$ sediaan nanoemulsi minyak kemiri akan muncul pada layar alat $\mathrm{pH}$ meter.

\section{Penetapan tipe nanoemulsi}

Tipe nanoemulsi minyak kemiri diidentifikasi dengan menggunakan metode dilusi. Sebanyak 1 gram nanoemulsi minyak kemiri dilarutkan dalam air sebanyak $100 \mathrm{~mL}$. Jika nanoemulsi terlarut sempurna maka sediaan termasuk dalam tipe nanoemulsi minyak dalam air (M/A).

\section{Pengukuran droplet}

Ukuran droplet nanoemulsi diukur dengan particle size analyzer dengan metode dynamic light scanering. Nanoemulsi minyak kemiri dituang ke dalam kurvet kemudian dimasukkan ke dalam sampel holder dan dilakukan analisis dengan instrumen.

\section{Persiapan hewan coba}

Hewan coba yang digunakan berupa kelinci jantan (Oryctolagus cuniculus) dengan usia 3 - 4 bulan dan berat $\pm 3 \mathrm{Kg}$ sebanyak empat ekor. Sebelum digunakan, hewan coba diaklitimasi selama satu minggu dan diberi makan ad libitum. Setelah satu minggu, punggung kelinci dicukur mengunakan gunting dan pisau cukur, kemudian dibagi menjadi 4 daerah dengan masing-masing sisi yang lebih kurang $2,5 \mathrm{~cm}$ dan antara daerah yang satu dengan daerah yang lain diberi jarak lebih kurang $3 \mathrm{~cm}$. Perlakukan berbeda diberikan pada 4 daerah pada punggung kelinci. Pada daerah 1 perlakuan pertumbuhan rambut yang diberikan minyak kemiri murni, daerah 2 kontrol (+) diberikan tonik rambut ginseng yang diperoleh di pasaran, daerah 3 merupakan kontrol (-) diberikan air suling, dan daerah 4 diberi perlakuan dengan formula nanoemulsi minyak kemiri. Perlakuan kepada hewan coba dilakukan satu kali sehari dan berlangsung selama 21 hari dengan volume $1 \mathrm{~mL}$. Seluruh prosedur percobaan telah mendapatkan surat laik etik internal Institut Ilmu Kesehatan Bhakti Wiyata Kediri dengan nomor 31/PP2M-KE/VI/2019.

\section{Uji aktivitas pertumbuhan panjang rambut}

Panjang rambut kelinci pada setiap perlakuan diamati pada hari ke- 8, 15 dan 22. Sebelum diukur, rambut dicabut sebanyak 10 helai yang terpanjang kemudian diletakkan pada kertas hitam. Untuk memudahkan pengukuran, rambut kelinci diletakkan pada selotip bening kemudian diukur panjangnya dengan jangka sorong.

\section{Uji aktivitas ketebalan rambut}

Pengukuran bobot atau ketebalan rambut dilakukan pada hari ke 22 dengan cara mencukur semua rambut pada masing-masing daerah yang di uji kemudian ditimbang menggunakan timbangan digital.

\section{HASIL DAN PEMBAHASAN}

Hasil uji mutu fisik sediaan nanoemulsi minyak kemiri tersaji pada Tabel 2.

Tabel 2. Hasil uji mutu fisik nanoemulsi minyak kemiri

\begin{tabular}{cc}
\hline Mutu Fisik & Hasil \\
\hline Organoleptis & Jernih, bau khas kemiri \\
$\mathrm{pH}$ & $5,47 \pm 0,029$ \\
Tipe Nanoemulsi & Minyak dalam air \\
Ukuran Droplet & $21,1 \mathrm{~nm}$ \\
Polydispersity Index & 0,338 \\
\hline
\end{tabular}




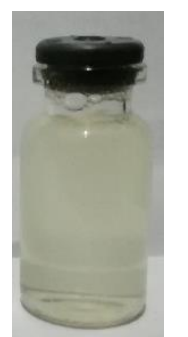

Gambar 1. Nanoemulsi minyak kemiri

Pembuatan nanoemulsi dengan bahan aktif minyak kemiri pada penelitian ini merupakan tahap awal untuk pembuatan sediaan kosmetik tonik rambut yang berfungsi untuk merangsang pertumbuhan rambut. Salah satu senyawa aktif yang diduga memiliki aktivitas sebagai perangsang pertumbuhan rambut dalam minyak kemiri adalah asam oleat. Minyak kemiri yang diformulasi dalam sistem penghantaran nanoemulsi ini diharapkan dapat meningkatkan penetrasi sehingga meningkatkan aktivitas penumbuhan rambut.

Pada uji organoleptis dilakukan secara visual dan diperoleh hasil nanoemulsi yang jernih. Sediaan yang jernih merupakan indikator bahwa sediaan tersebut memiliki ukuran droplet yang kecil. Hal ini dibuktikan dengan hasil uji ukuran droplet yang didapatkan hasil $21,1 \mathrm{~nm}$ dan polydispersity index sebesar 0,338 . Hasil uji ukuran droplet dan polydispersity index yang mendekati 0 tersebut, telah sesuai dengan persyaratan nanoemulsi yang merupakan larutan yang homogen, transparan, dengan ukuran droplet antara $10-100 \mathrm{~nm}$ (Agrawal \& Agrawal, 2012).

Formulasi nanoemulsi minyak kemiri yang dibuat menggunakan kombinasi surfaktan nonionik yaitu span 80 dan tween 80. Surfaktan nonionik dipilih karena lebih aman dibandingkan jenis surfaktan lain dalam hal timbulnya iritasi pada kulit (Santos dkk., 2008; Kumar dkk., 2010). Selain itu, kombinasi surfaktan lipofil (span 80) dan hidrofil (tween 80) untuk mendapatkan sistem nanoemulsi minyak dalam air dengan HLB sistem yang diinginkan. Sementara itu, dipilih kosurfaktan yang cenderung memiliki atom $\mathrm{C}$ yang lebih pendek yaitu etanol yang juga memiliki efek untuk meningkatkan penetrasi pada sediaan transdermal (Rowe dkk., 2009).

Hasil pengukuran $\mathrm{pH}$ sediaan nanoemulsi minyak kemiri menunjukkan nilai rata-rata sebesar 5,47 \pm 0,029 . Menurut SNI, nilai $\mathrm{pH}$ tonik rambut yang baik berada pada kisaran 3,0 - 7,0 sehingga sediaan yang dihasilkan tidak mengiritasi kulit. Sementara pada hasil uji tipe nanoemulsi yang telah dilakukan dengan metode dilusi atau pengenceran, nanoemulsi minyak kemiri memiliki tipe minyak dalam air (M/A) yang ditandai dengan sediaan nanoemulsi larut sempurna dalam air. Pembuatan emulsi dengan tipe minyak dalam air diharapkan dapat lebih diterima ketika digunakan dan tidak menimbulkan rambut menjadi berminyak. Uji pertumbuhan rambut dengan hewan coba kelinci selama 21 hari tersaji pada Tabel 3.

Tabel 3. Hasil uji pertumbuhan rambut kelinci

\begin{tabular}{|c|c|c|c|c|}
\hline \multirow{2}{*}{ 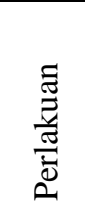 } & \multicolumn{3}{|c|}{$\begin{array}{l}\text { Rata-rata pertumbuhan } \\
\text { rambut hari ke- }(\mathrm{cm})\end{array}$} & \multirow{2}{*}{$\begin{array}{c}\text { Laju } \\
\text { pertumbuhan } \\
\text { rambut } \\
(\mathrm{cm} / \mathrm{hari})\end{array}$} \\
\hline & 8 & 15 & 22 & \\
\hline MK & 1,35 & 1,38 & 1,37 & 0,06 \\
\hline $\mathrm{K}(+)$ & 1,32 & 1,58 & 2,22 & 0,10 \\
\hline $\mathrm{K}(-)$ & - & - & 0,77 & 0,03 \\
\hline V & 1,58 & 1,92 & 2,97 & 0,13 \\
\hline
\end{tabular}

MK : Menggunakan minyak kemiri murni $100 \%$

$\mathrm{K}(+)$ : Menggunakan tonik rambut ginseng.

$\mathrm{K}(-)$ : Menggunakan air suling

NE : Menggunakan nanoemulsi minyak kemiri

Data pada Tabel 3 menunjukkan bahwa daerah yang diberikan perlakuan nanoemulsi minyak kemiri memiliki ukuran panjang rambut yang paling besar dibandingkan tiga kelompok perlakuan lainnya. Ukuran droplet nanoemulsi yang kecil dapat menembus stratum korneum pada kulit kepala dengan lebih mudah dibandingkan sediaan dengan ukuran droplet yang lebih besar.

Selain memiliki laju pertumbuhan rambut yang paling cepat, dapat dilihat bahwa nanoemulsi minyak kemiri juga dapat meningkatkan ketebalan rambut. Uji ketebalan rambut kelinci yang dilakukan pada hari ke22 tersaji pada Tabel 4 .

Tabel 4. Hasil uji ketebalan rambut kelinci hari ke-22

\begin{tabular}{cc}
\hline Perlakuan & $\begin{array}{c}\text { Rata-rata ketebalan } \\
\text { Rambut (gram) }\end{array}$ \\
\hline MK & $0,191 \pm 0,002$ \\
K (+) & $0,145 \pm 0,009$ \\
K (-) & $0,006 \pm 0,001$ \\
NE & $0,287 \pm 0,00$
\end{tabular}

MK : Menggunakan minyak kemiri murni 100\% $\mathrm{K}(+)$ : Menggunakan tonik rambut ginseng.

$\mathrm{K}(-)$ : Menggunakan aquadest

$\mathrm{NE} \quad$ :Menggunakan nanoemulsi minyak kemiri

Hasil penelitian ini, dapat menjadi tahap awal pengembangan sediaan tonik rambut dengan sistem nanoemulsi yang memiliki aktivitas lebih baik dibandingkan sediaan konvensional. 


\section{KESIMPULAN}

Nanoemulsi minyak kemiri dengan kadar 5\% dapat mempercepat pertumbuhan dan ketebalan rambut dibandingkan minyak kemiri konvensional.

\section{UCAPAN TERIMAKASIH}

Terima kasih kepada Yayasan Bhakti Wiyata yang telah memberikan kesempatan kepada peneliti untuk menyelesaikan penelitian dan mempublikasikan hasil penelitian.

\section{DAFTAR PUSTAKA}

Agrawal, O. P. \& Agrawal, S. (2012). An Overview of New Drug Delivery System: Nanoemulsion. Asian Journal of Pharmaceutical Science and Technology; 2; 5-12.

Agoes, G. (2015). Sediaan Kosmetik (SFI-9). Bandung: Institut Teknologi Bandung.

Arlene, A. (2013). Ekstraksi Kemiri dengan Metode Soxhlet dan Karakterisasi Minyak Kemiri. Jurnal Teknik Kimia Usu; 2; 6-10.

Gupta, P. K., Pandit, J. K., Kumar, A., Swaroop, P. \& Gupta, S. (2010). Pharmaceutical Nanotechnology Novel Mikroemulsion-High Energy Emulsification Preparation Evaluation and Application. The Pharma Research; 3; 117139.

Kumar, B., Jain, S. K., Prajapati, S. K., Mahor \& Kumar, A. (2010). Development and Characterization of Transdermal Microemulsion Gel for an Antiviral Drug. International Journal of Pharmaceutical Science and Research; 1 ; 57-73.
Lina, N. W. M., Maharani, T., Sutharini, M. R., Wijayanti, N. P. A. D. \& Astuti, K. W. (2017). Karakterisasi Mikroemulsi Ekstrak Kulit Buah Manggis (Garcinia mangostona L.). Jurnal Farmasi Udayana; 6; 6-10.

Nurjanah, N. \& Krisnawati, M. (2014). Pengaruh Hair Tonic Lidah Mertua (Sanseviera trifasciata Prain) dan Seledri (Apium graveolens Linn) untuk Mengurangi Rambut Rontok. Journal of Beauty and Beauty Health Education; 3; 1-8.

Rowe, R. C., Sheskey, P. J. \& Quinn M. E. (2009). Handbook of Pharmaceutical Excipients, Sixth Edition. London: The Pharmaceutical Press.

Santos, P., Watkinson A. C., Hadgraft, J. \& Lane, M. E. (2008). Application of Microemulsion in Dermal and Transdermal Drug Delivery Skin. Pharmacology Physiology; 21; 248 - 250

Sari, D. K. \& Wibowo, A. (2016). Perawatan Herbal pada Rambut Rontok. Medical Journal of Lampung University; 5; 129-134.

Ulfah, A. M. (2003). Aktivitas Ekstrak Etanolik Biji Kemiri (Aleurites moluccana L. Wild) sebagai Pemicu Pertumbuhan Rambut Kelinci Putih Jantan serta Uji Kualitatif Kandungan Kimianya. Skripsi; Fakultas Farmasi Universitas Gadjah Mada, Yogyakarta.

Vivek P. C. (2019). Nanotherapeutics and Nanobiotechnology In: Shyam S. M, Shivendu R., Nandita, D., Raghvendra, K. M., Sabu, T. (ed.) Micro and Nano Technologies, Applications of Targeted Nano Drugs and Delivery Systems; 1-13. Amsterdam: Elsevier. 